\title{
Cartografia de uma Prática Pedagógica em Variação
}

\author{
Cartografía de una Práctica Pedagogica en Variación \\ Cartography of a Pedagogical Practice in Variation
}

\author{
Josimara Wikboldt Schwantz ${ }^{1}$ \\ Carla Gonçalves Rodrigues ${ }^{2}$
}

\begin{abstract}
Resumo
Este trabalho se constitui num atlas ao inventariar um estilo docente. Atua com intercessor filosófico Deleuzeguattariano, literário kafkiano e científico educacional. Dispara um modo de pensar, filosoficamente, sobre a temática docência, na ação de ler as margens e escrever nos excessos de um arquivo escrileituras da Oficina Conatus, realizada com professores. $\mathrm{Na}$ imersão da leitura-escritura do arquivo, um conjunto de mapas são desenhados. O primeiro diz das matérias literárias, filosóficas e científicas experimentadas na Oficina como intercessoras para ler-escrever. E o segundo conjunto de mapas ocupado em pontuar rastros a partir de signos que são emitidos das escrileituras radiofônicas criadas pelos professores: No rastro do nome próprio emerge um coletivo de vozes que se despersonaliza para dizer sobre sua profissão. Pelo olhar, mostra-se a experiência de abrir coisas e palavras, colocando-se além do que está dado a ver. O som advém como uma linha de fuga, em que a forma de expressão pela música ou, até mesmo por um ruído, destaca-se como uma saída para desbloquear territorialidades opressoras vivenciadas num cotidiano escolar. A doença, tida como parada do processo, se refaz no proveito de aí recuperar uma potência para continuar a viver. Apostamos na experimentação de escrileituras. Com isso, passamos pelo desejo de intensificar as experiências notáveis na trajetória docente, no que produziram e ainda produzem em matéria de escrita e pensamento.
\end{abstract}

Palavras-Chave: Cartografia; Educação; Escrileituras; Filosofia da diferença; Literatura.

\section{Resumen}

Este trabajo se constituye en un atlas al inventariar un estilo docente. Actúa como intercesor filosófico Deleuzeguattariano, literário kafkaniano y científico educacional. Dispara un modo de pensar, filosóficamente, sobre la temática docencia, en la acción de leer los márgenes y escribir en los excesos de un archivo escrilecturas del Taller Conatus, realizado con profesores. En la inmersión de lectura escrita del archivo, un conjunto de mapas son dibujados. El primero dice de las materias literarias, filosóficas y científicas experimentadas en el Taller como intercesoras para leer y escribir. Y el segundo conjunto de mapas ocupado en puntuar rastros a partir de signos que son emitidos de las escrilecturas radiofónicas creadas por los profesores. En el rastro del nombre propio emerge un colectivo de voces que se despersonaliza para decir sobre la profesión. Por la mirada, se muestra la experiencia de abrir cosas y palabras, puestas más allá de lo que se puede ver. El sonido adviene como una línea de fuga, en que la forma de expresión por la música, o hasta mismo por un ruido, se destaca como una salida para desbloquear territorialidades opresoras vividas en un cotidiano escolar. La enfermedad, vista como una parada en el proceso, se rehace en el provecho de ahí recuperar una potencia para seguir viviendo. Apostamos en la experimentación de las escrilecturas. Con ello, pasamos por el deseo de intensificar las experiencias notables en la trayectoria docente, en lo que han producido y todavía producen en materia de escrita y pensamiento.

Palabras claves: Cartografía; Educación; Escrilecturas; Filosofía de la Diferencia; Literatura.

${ }^{1}$ Mestra em Educação; Doutoranda em Educação pelo Programa de Pós-Gaduação em Educação da Universidade Federal de Pelotas; Bolsista CAPES; Pelotas, Rio Grande do Sul, Brasil; josiwikboldt@ hotmail.com

${ }^{2}$ Doutora em Educação; Docente na Universidade Federal de Pelotas; Pelotas, Rio Grande do Sul, Brasil; cgrm@ufpel.edu.br 


\begin{abstract}
This work constitutes a atlas when inventorizing a teaching style. It works with Deleuzoguattarian philosophical, Kafkian literary and educational scientifical intercessors. It shoots a way of thinking philosophically about teaching on the action of reading the margins and writing on the excesses of a writreadings file of the Conatus Workshop, realized with teachers. In the immersion in the read-write file, a set of maps are drawn. The first set of maps say about the literary, philosophical and scientific subjects experienced in the Workshop as intercessors for reading-writing. The second set is occupied on punctuating traces from signs that are emitted from the radio soap operas created by the teachers. In the trace of the proper name emerges a collective of voices that is depersonalized to say about this profession. Through the look, one shows the experience of opening things and words, putting oneself beyond what is given to see. Sound comes as a line of flight, in which the form of expression through music, or even by a noise, stands out as an outlet to unlock oppressive territorialities experienced in a school routine. The disease, considered as a halt in the process, is recovered in the benefit of recovering a power to continue living. We bet on the experimentation of writing. This way, we go through the desire to intensify remarkable experiences in the teaching trajectory, in what they have produced and still produce in matters of writing and thinking.
\end{abstract}

Keywords: Cartography; Education; Writreadings; Philosophy of difference; Literature.

\title{
1. Introdução
}

A pesquisa apresentada neste trabalho percorre caminhos da docência enquanto temática educacional. Buscamos rastrear, cartograficamente (DELEUZE; GUATTARI, 1995a), uma experimentação realizada com professores em formação inicial e continuada, no encontro daquilo que diz de uma prática pedagógica em variação e das constituições subjetivas de uma professoralidade em transformação. Tivemos por objetivo mapear as condições de possibilidade para a constituição de estilo(s) na docência.

Tal propósito se justifica pela inquietação denotada na produção realizada pelos professores (atuantes de escola pública, em formação inicial e continuada) em cinco edições de realização da Oficina Conatus (uma proposição do Projeto Escrileituras: um modo de lerescrever em meio à vida, núcleo UFPel), em que foi cartografado a respeito da docência, escrileituras radiofônicas criadas no agenciamento de matérias literárias, filosóficas e científicas. Considerando as poucas condições atualmente oferecidas para conversarem, pensarem, escreverem e lerem nos espaços escolares e de formação, vimos esta experiência como disparador para problematizar a docência em meio à vida, através do ato de criação textual em escrileituras (CORAZZA, 2011).

Vimos a importância desta pesquisa na medida em que mapeia um arquivo, no encontro de condições de possibilidades para que a docência possa inventar outros fazeres e dizer daquilo que diminui e, por vezes, aumenta a potência de ação no cotidiano da escola. Este movimento permitiu questionar sobre se há, ainda, diante das circunstâncias que acometem a categoria (desvalorização, baixos salários e condições de trabalho, adoecimento, 
etc), motivos para mudar a perspectiva e o propósito pedagógico e existencial em suas carreiras.

Financiado pela Coordenação de Aperfeiçoamento de Pessoal de Nível Superior (CAPES), este Projeto tratou de pensar a educação com e em meio à vida, implicou ensinar e aprender a partir do ato de criação textual, no agenciamento de diferentes áreas do conhecimento. Assim, realizou atividades de Oficinas pelo país durante quatro anos (20102014), nas diferentes modalidades de ensino e para diferentes públicos (Professores e estudantes). Desenvolveu a leitura e a escrita como via de mão dupla, aberta às interferências do leitor e, portanto, lido e escrito de variadas formas. Remeteu-se à criação de uma escritura inspiradora e cheia de ideias, capaz de produzir a diferença em seu exercício, deixando de lado as reproduções que inibem a capacidade de invenção.

O problema da pesquisa vem atrelado ao movimento lançado pelo "objeto" do arquivo do Projeto, dissolvendo-se como um fluxo que nos colocou a caminhar: Como a constituição de estilo(s), por meio do exercício de escrileituras, afeta os modos de ser professor? Pensamos a questão do estilo, não somente literário (daquilo que escreve um docente), mas em termos existenciais e pedagógicos, o que é posto em movimento, composição, variação e fuga (elementos do estilo) na prática docente? Nosso desafio, nesta investigação, é promover um espaço para pensar sobre os processos de formação da docência, bem como de suas condições de possibilidades de variar o exercício sobre habilidades e competências aprendidas. Observar o que a docência pode criar e relacionar durante o processo de constituição do ser professor.

Trazemos a contribuição teórica da filosofia deleuze-guattariana com o conceito de estilo (DELEUZE, 1997; 2010), (DELEUZE; PARNET, 1997; 1998), (DELEUZE; GUATTARI, 1995a; 2014). Constatamos que é tratado a partir de dois aspectos: o primeiro refere-se à possibilidade de destituir uma ordem preestabelecida na língua pondo a variá-la de modo que se crie, no próprio idioma, uma língua estrangeira. O segundo aspecto refere-se a um modo de levar a linguagem até um limite, produzindo uma espécie de música, outro idioma estrangeiro na língua materna. Para tal ação, há de se ter uma necessidade que move sua produção.

Deleuzianamente falando, o estilo vem do desejo de devastar o significado em detrimento do sentido, ao criar novas sintaxes. Consideramos esta sintaxe um componente do sistema linguístico que determina as relações formais de construção das frases a partir da composição de palavras. Coloca em variação uma determinada estrutura. Buscamos articular esta relação do conceito com a docência, de modo a destituir uma ordem preestabelecida, que atribui modelos para a execução das práticas pedagógicas em sala de aula, como a utilização 
de livros e métodos didáticos específicos; o seguimento a uma sequência lógica e de complexidade no desenvolvimento de conteúdos disciplinares; como agir e pensar sua prática. E, do mesmo modo, levar a docência até um limite, encontrando uma linha de escape para o que lhe aprisiona e, consequentemente adoece.

\section{Cartografando uma prática em escrileituras}

Escrever o método põe a falar daquilo que estamos em vias de aprender. Não se trata apenas de descrever etapas de um desenvolvimento, mas tecer os caminhos do cultivo e refinamento necessários para o crescimento da pesquisa (PASSOS; KASTRUP; ESCÓSSIA, 2012). A Oficina Conatus, enquanto uma prática em escrileituras (CORAZZA, 2011), aconteceu cinco vezes ( 5 edições) e com diferente público docente ${ }^{3}$. Refere-se a uma proposta de experimentação de escrita-leitura a partir de matérias literárias (A metamorfose de Kafka; O discurso do urso de Cortázar; Mania de explicação de Adriana Falcão), filosóficas (conceito de Conatus para Spinoza; Eterno retorno em Nietzsche) e científicas (o mal-estar e a [trans]formação dos professores).

Estas matérias foram a aposta para acionar o movimento de escrileituras nos participantes, na medida em que nos preocupávamos menos em como os professores escreveriam e/ou leriam, mas em como determinadas matérias (da arte, da filosofia e da ciência) poderiam potencializar um pensamento, deslocando-o de um senso comum sobre discursos introjetados na profissão. Durante a Oficina, discutimos sobre o adoecimento docente. Mediante estas proposições, os docentes escreveram e leram; criaram personagens e gravaram cenas em formato de novelas radiofônicas.

Estas escrileituras radiofônicas, atualmente compõem os arquivos do Projeto escrileituras (CORAZZA, 2011). Um conjunto de materiais, das mais diferentes formas (vídeos, músicas, escrileituras radiofônicas, livros, poesia, forografias) produzidos durante os quatro anos de realização do Projeto. As 15 escrileituras radiofônicas produzidas a partir da Oficina Conatus serviram para a composição cartográfica do método, de modo a dar forma e conteúdo à expressão analítica vindoura.

Traçamos o desenho de mapas, constituindo um atlas: conjunto de mapas extensivos (das matérias e dos rastros) e de mapas intensivos (criação de um bestiário docente).

\footnotetext{
${ }^{3}$ A $1^{\text {a }}$ edição foi oferecida ao Cpers-Sindicato (Centro dos Professores do Estado do Rio Grande do Sul), núcleo Rio Grande (2012). A $2^{\mathrm{a}}$ (2013), $4^{\mathrm{a}}$ (2015) e $5^{\mathrm{a}}$ (2016) edição oferecida aos estudantes em formação na Faculdade de Educação, UFPel, promovidas através de cursos de curta duração (Seminário Espíritos Livres e Seminário Subjetividades Contemporâneas) e a $3^{\text {a }}$ edição realizamos com professores de uma escola da rede estadual de ensino (2013).
} 
Apresentaremos aqui apenas o primeiro conjunto de mapas, os extensivos. Referem-se ao plano de trajetos enquanto território histórico mundial. Foram compostos a partir da captura dos fluxos de utilização das matérias em cada uma das cinco edições da Oficina (Mapa 1 mapas extensivos das matérias da Oficina Conatus); e dos rastros capturados da audição das 15 escrileituras radiofônicas produzidas pelos professores participantes (Mapa 2 - mapas extensivos dos rastros extraídos das escrileituras radiofônicas.

Como chegamos a esta configuração de mapas? Para a construção do primeiro conjunto de mapas (Mapa 1), capturamos acontecimentos das Oficinas registrados em atas de reuniões do Núcleo UFPel do Projeto Escrileituras, da dissertação de mestrado de SILVA (2014) e de um dos cadernos de anotações em que registrávamos o movimento criador das edições (planejamento e realização).
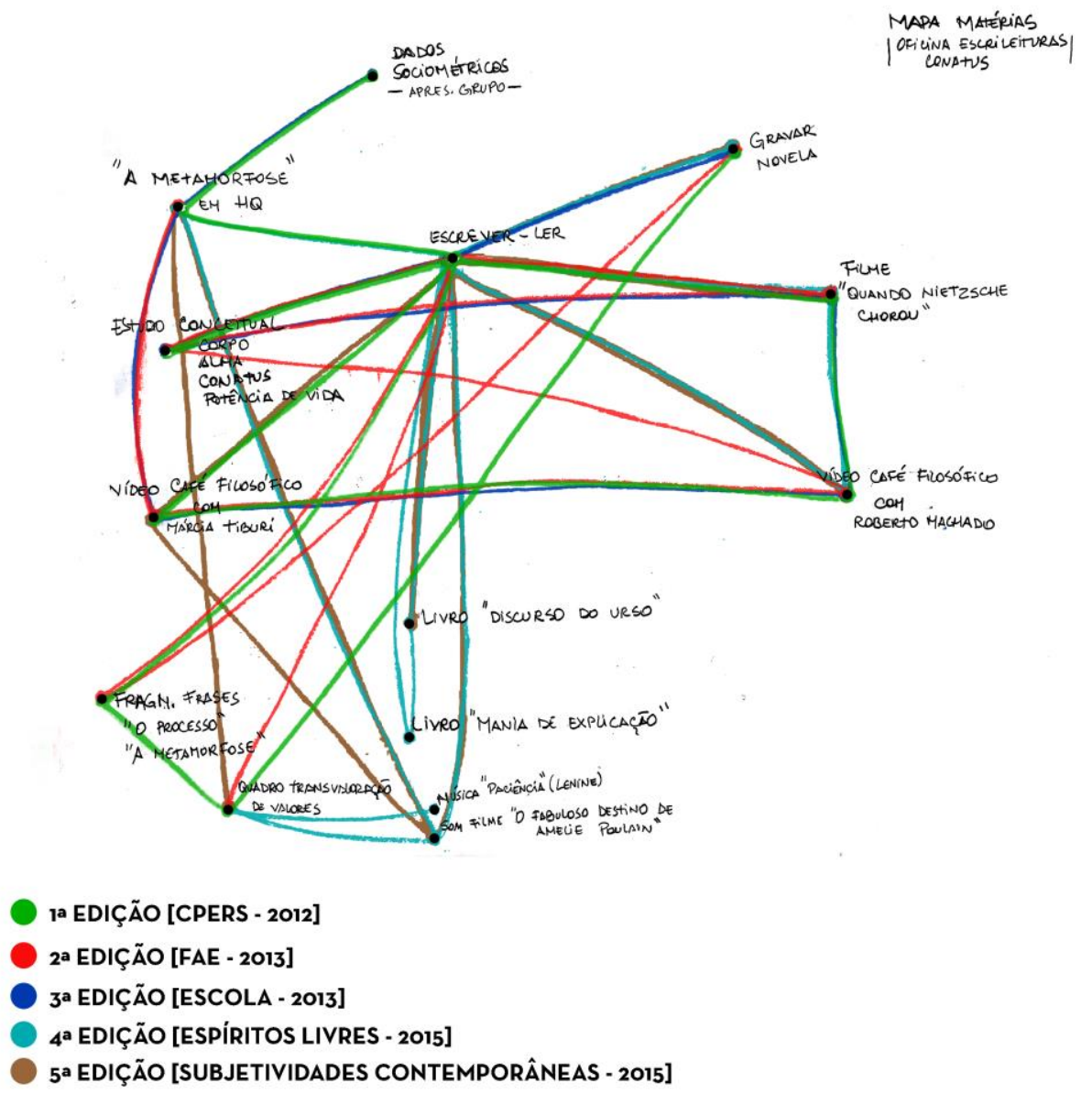

Mapa 1 - Sobreposição de mapas extensivos das matérias da Oficina Conatus. Fonte: Das autoras

Em um plano extensivo, escrevemos o nome de cada uma das matérias utilizadas como agenciamento. Para cada edição, desenhamos um mapa (num total de cinco mapas), onde traçamos linhas do movimento com que cada uma das matérias foi sendo oferecida e o modo 
como fomos variando-as em sua apresentação: por vezes intercalávamos com as paradas para o escrever-ler, inseríamos outras matérias neste intervalo ou, até mesmo, deixávamos algumas de lado. Este percurso proliferou linhas de um segmento pedagógico. Experimentamos modos de fazer, modos de escrever-ler, na busca por aberturas para que algo pudesse passar, atravessar os discursos já instituídos sobre o comportamento e a saúde dos docentes, pois este era o objetivo da Oficina Conatus naquela circunstância.

O segundo conjunto de mapas (Mapa 2), o das escrileituras radiofônicas, surge da escuta da gravação e da leitura da transcrição realizada de cada uma das 15 criações. Esta tarefa fortaleceu a captura de 14 rastros que suscitaram em nós, pesquisadoras. Alguns deles surgiram em função da temática propositora da Oficina como doença, vida e eterno retorno. Outros, do próprio ato de criação, onde os participantes trouxeram tais elementos: riso, som, olhar, nome próprio, potência de criação. Houveram rastros que não passaram da repetição de um queixume desmedido percebido antes mesmo das Oficinas acontecerem: desprestígio social, segurança e transformação da Educação. E, também, aqueles que, simplesmente, saltaram aos nossos ouvidos como discurso maior, uma temática nova que surgia ali: esperança, repetição, machismo.

Assim, todos estes itens capturados foram dispostos numa folha como pontos. Traçamos linhas entre um ponto e outro a partir de cada uma das escrileituras escutadas, conectando-os. As linhas cruzavam, por vezes, um mesmo caminho, na medida em que ligavam um ponto a outro. Deste exercício, traçamos um plano de composição, absorvendo os mais recorrentes para o movimento analítico. São eles: Nome próprio, Olhar, Som, e Doença.

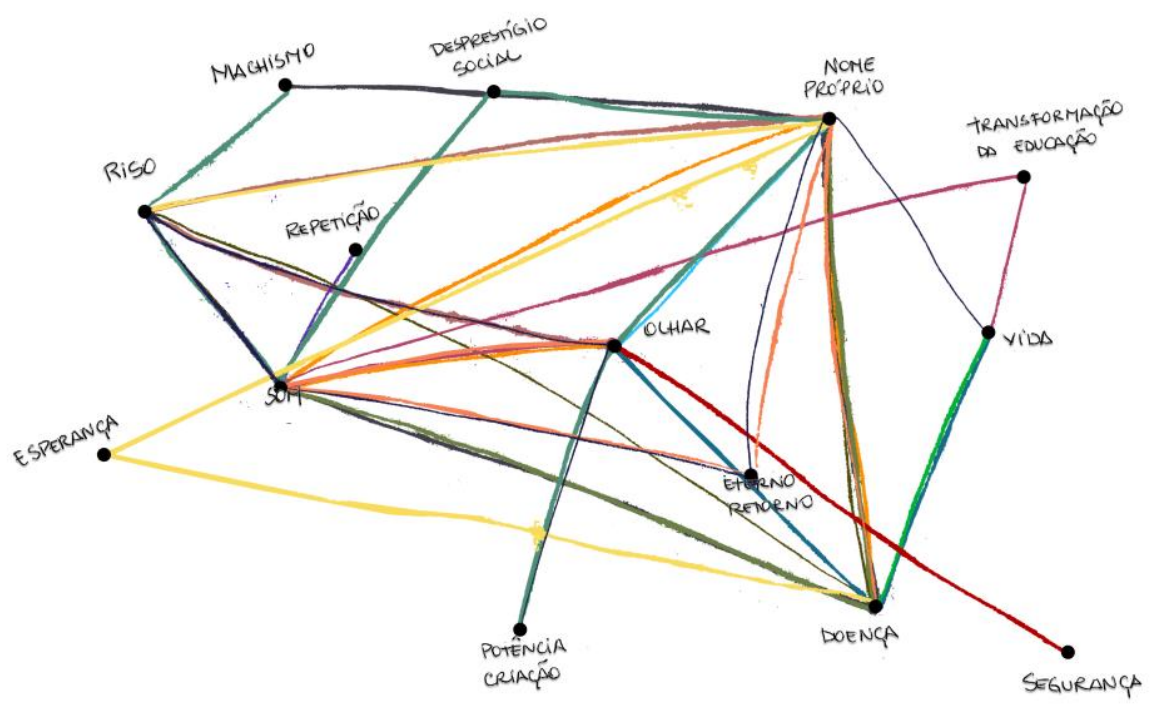




COSTUCANTAR OlANDO
DORIVALDO
TIMÓTEO
A VACA
O CIRCO
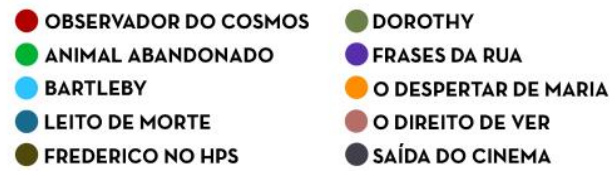

Mapa 2 - Sobreposição de mapas extensivos dos rastros extraídos das escrileituras radiofônicas.

Fonte: Das autoras

Considerando a cartografia como um método que acompanha processos (PASSOS; KASTRUP; ESCÓSSIA, 2012), apostamos nessa direção de distribuição e sobreposição de mapas extensivo e intensivos, promovendo o efeito rizoma, conforme indicam Deleuze Guattari (1995a). Trata-se de conectar um ponto a outro qualquer, não opondo-os como dois modelos, mas atribuindo percursos que não param de se deslocarem, criando outras saídas e entradas, constituindo-se em multiplicidades. Dessa maneira, os planos facilitam enxergar um percurso de acontecimentos a partir de um meio (DELEUZE, 1997). Este atlas possibilita acompanhar um desenvolvimento de trajetos e devires que mobilizam uma docência para resistir sobre aquilo que tenta irromper seu processo de existir.

\section{Resultados e Discussão}

Em relação ao mapeamento extensivo das matérias da Oficina Conatus, extraímos fluxos, singularidades e traços (selecionados, organizados e estratificados) a dar consistência artificial ou natural, tratando-se de um "agenciamento como verdadeira invenção" (DELEUZE; GUATTARI, 2012b, p. 94). Há diferentes maneiras de se começar uma Oficina. Há diferentes jeitos para operacionalizar um conteúdo para que daí manifeste-se uma expressão.

Enxergamos mudanças e repetições em cada uma das edições da Oficina, de modo que as matérias também foram sendo distruídas. Esta variação dependeu do público participante, dos elementos que incluíamos e excluíamos, do tempo e do espaço proporcionado. Entendemos, como um resultado, que as circunstâncias que fazem os docentes criarem, em seus atos pedagógicos, são disparadas por acontecimentos e pelas relações entre diferentes campos de conhecimento de que são capazes de fazer.

Vimos que uma das soluções encontradas por eles, no que dizia sobre o adoecimento, foi duvidar dos discursos já dados e poder acionar saídas para aquilo que, de fato, vem diminuindo a potência de agir docente. As matérias (da arte, da filosofia e da ciência) se valeram na desmontagem do funcionamento de uma estrutura do pensamento dos docentes em 
relação a suas práticas e seus modos de compreensão daquilo que altera a potência de suas vidas.

Este mapeamento extensivo das matérias também sinalizou a produção de velocidades e intervalos (DELEUZE; GUATTARI, 1995b) de uma escrileitura que dizia da docência em meio a cenas fabuladas e reais. Também nos diz de um fluxo que se movimenta e varia de acordo com cada circunstância vivenciada nas Oficinas. Na medida em que alguns conceitos filosóficos e discussões foram sendo arraigadas, abriu-se a oportunidade para acoplar outros elemento considerados com força para orientar ou reorientar novamente os caminhos percorridos. Desenvolveram outras estratégias para expressar sobre a problemática anunciada naquela imanência, como percebido na escrileitura radiofônica intitulada de Frases $d a$ rua ${ }^{4}$ e A vaca.

Entradas e saídas para os ditos e não ditos sobre uma docência despontecializada que adoece floresceram daqueles que experimentavam dizer algo em relação com a literatura kafkiana, o conceito filosófico de Nietzsche e Spinoza, o Discurso do urso de Cortázar, etc. Um exercício que fez movimentar pensamentos nos participantes da Oficina, indagando e desconfiando de um senso comum proliferado em torno do que se passa com a saúde dos professores.

Sobre o mapeamento extensivo das escrileituras radiofônicas, destacam-se rastros como signos emitidos as pesquisadoras. O que cada rastro nos fez pensar? Por que estes e não outros? Cada um dos pontos que elegemos poderiam terem sido outros ou multiplicarem-se em muitos. Foram possíveis na relação que se efetivou na imanência de uma superfície de sensibilidade entre pesquisadoras e arquivo.

No rastro do nome próprio apresenta-se uma despersonalização manifestada no instante em que o encontro com outras vozes, formas de ver e dizer a profissão docente se fundem. A criação de personagens, para falar de uma vida, estabeleceu novas conexões e mutações de matéria e função, fazendo emergir não somente uma identidade una, mas um estado subjetivo múltiplo (DELEUZE; GUATTARI, 1995a), extraindo daí um coletivo de mundos díspares, agenciando, naquele que escreve, um "outro de si, composto de muitos" (CRIZEL, MUNHOZ, 2016, p. 947). Porque conta histórias de vidas, dos sonhos do João, da Maria, da Michele, do Tiago, do Mateus, do Gabriel, da Rosa e por aí vai ${ }^{5}$, deixa impregnar uma força acometida pelos encontros que se efetivam (DELEUZE; GUATTARI, 2012a). Encontros

\footnotetext{
4 As escrileituras radiofônicas podem ser escutadas neste link: https://www.youtube.com/playlist?list=PLtutsvBvUTTM4jd4reISfSjiV_C4XCN17

${ }^{5}$ Fragmento da escrileitura radiofônica Costucantarolando.
} 
estes, sejam eles na escrita, na leitura, ou na audição das escrileituras radiofônicas, que dizem dos sonhos e cenas de uma vida de professora (CORAZZA, 2005).

Pelo olhar, mostra-se a experiência de abrir coisas e palavras, colocando-se além do que está dado a ver (DELEUZE, 2012). Olhando para o seu corpo, percebe fissuras em si ${ }^{6}$. A observação pelo olhar manifesta a abertura de um portal por onde aprendemos a se abrir ao outro. Trata-se, também, de um trespassamento de fronteiras subjetivas que nos põe em relação com outras formas de existência. O tempo destinado a olhar torna-se necessário para um amadurecimento do próprio ato pedagógico, principalmente nesta contemporaneidade, onde somos interpelados pelos fluxos da rapidez e da superficialidade das relações.

O som advém como uma linha de fuga (DELEUZE; GUATTARI, 2014), de modo que a forma de expressão pela música ou, até mesmo por um ruído animal, busca uma saída para desbloquear uma territorialidade opressora vivenciada por indivíduos num coletivo escolar. Ela aponta a janela (som de saxofone). Olha, ouçam a música! Vamos pra lá, vamos dançar! Vamos procurar outra forma pra gente (som de saxofone) $(\mathcal{S})^{7}$. Aquele som anômalo produziu potências de desterritorialização (SAUVAGNARGUES, 2006), uma saída daquele lugar comum ao qual personagens se submetiam, onde sentiam sua força de agir diminuída (SPINOZA, 2007). Não se tratava apenas de manter uma forma de existência dada a uma professoralidade, mas de um processo que proporciona encontrar brechas de respiro.

A doença apareceu como outro elemento recorrente nas escrileituras radiofônicas dos professores. Considerada como parada do processo (DELEUZE, 1997) se refaz no proveito de aí recuperar uma potência, um conatus (SPINOZA, 2007), causando um esforço para continuar a viver. Queria estar em outra dor, não mais nessa ${ }^{8}$. As escrileituras foram produzidas no sintoma, desafiando seus mal-estares. Cavando valos por onde algum suco pudesse passar, os professores despertaram, a partir de personagens ora fabulados, ora reais, um modo de ser e fazer que ali cindia: ao invés de quebrar-se, abre-se um broto. Maria não morre, vira flor?.

Dizer que há uma saúde a se tirar de exemplo é afirmar e fortalecer as vozes de uma medicina moral (NIETZSCHE, 2012) que está sempre pronta a nos dizer como bem ou mal viver. Nossa virtude, em sua singularidade, é a saúde de nossa alma. Tal virtude dependerá daquilo que exerce (força, impulsos e erros) ao determinar o que de fato é saúde para um corpo. Existem doenças, mas também, diferentes saúdes do corpo e da alma. Esta "exclusiva

\footnotetext{
${ }^{6}$ Fragmento da escrileitura radiofônica $O$ despertar de Maria.

${ }^{7}$ Fragmento da escrileitura radiofônica Frederico no HPS.

${ }^{8}$ Fragmento da escrileitura radiofônica Leito de morte.

${ }^{9}$ Fragmento da escrileitura radiofônica $O$ despertar de Maria.
} 
vontade de saúde não seria um preceito, uma covardia e talvez um quê de refinado barbarismo e retrocesso" (Ibid, p. 135)? As escrileituras, neste percurso cartográfico, manifestou-se como um empreendimento em cada rastro, na fusão de vozes de um coletivo em nome próprio; na abertura ao outro pelo olhar; na busca por uma saída, pela sonoridade, daquilo que diminui nossa força de agir; na contramão de uma doença, busca-se variar discursos e práticas afirmativas sobre a consagração de um único estilo de professar.

\section{A cartografar...}

Ao retomar a questão que nos mobiliza nesta pesquisa, podemos afirmar que o movimento de escrileituras, no agenciamento de diferentes matérias da arte, da filosofia e da ciência dinamiza o exercício docente, na constituição de estilo(s). Esta constituição é promovida a partir da destituição de uma ordem preestabelecida que enuncia modos de ser e fazer a profissão, levando a docência até um limite, ao causar efeitos nos componentes estilísticos, de acordo com a perspectiva filosófica deleuze-guattariana: o movimento do pensamento, a composição em relação com matérias heterogêneas, a variação de determinado funcionamento e a fuga de uma prática pedagógica que diminui a potência de agir.

Apostamos, para estes efeitos, na experimentação da leitura-escrita, como via de mão dupla, uma escrileitura. Um aprender que, também, se faz em duas vias, do processo e da transformação. Não se sai do mesmo jeito que se entrou. Este rizoma exigiu uma predisposição a mudança.

O mapeamento extensivo da pesquisa nos favoreceu compor uma trajetória históricomundial de uma docência, em suas dores, alegrias, prazeres, desconfianças. Não se trata apenas de mostrar a extensão de um interior, mas nos interessa mais a maneira pela qual esta trajetória é determinada, levando seu interior a diferenciar-se (DELEUZE, 1997). Na compreensão filosófica adotada, entendemos que este plano se compõe com outro, em sua intensividade, de maneira a capturar forças que produzem um estado de sensação constituídos de uma extensividade, desde a condição da experiência em escrever-ler-pensar. Este último movimento cartográfico está sendo construído. Continuemos a cartografar uma prática pegagógica em variação de escrileituras.

Deixamos de lado aquilo que somos para então nos tornar outra coisa em nossa docência, nem pior, nem melhor, apenas outra. A afirmação da vida torna-se disparadora de saídas, em meio às escrileituras. Tem favorecido o aumento da potência de existir em detrimento de uma doença que tenta parar este processo, culminando num adoecimento. A 
pesquisa nos colocou, desde o início, em uma posição de aprendiz-cartógrafa-docente, onde recorrer à reprodução de opiniões levianas foi o primeiro passo aprendido naquilo que não servia mais para problematizar um ato pedagógico. $\mathrm{O}$ objeto da pesquisa disparou uma vontade de investigar estilo(s), numa pedagogia que tem a vida como princípio. Passamos pelo desejo de intensificar as experiências notáveis de uma trajetória docente, no que produziram e ainda podem produzir em matéria de pensamento.

\section{Referências}

CORAZZA, S. M. Uma vida de professora. Ijuí: Ed. Unijuí, 2005.

CORAZZA, S. M. Projeto de pesquisa: Escrileituras: um modo de "ler-escrever" em meio à vida. Plano de trabalho. OBS da Educação. Edital 038/2010. CAPES/ INEP. Programa de Pós-Graduação em Educação da UFRGS, setembro de 2011.

CRIZEL, A. P.; MUNHOZ, A. V. Por uma pedagogia que fale em nome próprio. ETD Educação Temática Digital, v. 18, n. 04, p. 942-954, out./dez. 2016. ISSN 1676-2592. Disponível em: https://periodicos.sbu.unicamp.br/ojs/index.php/etd/article/view/8642175. Acesso em: 05 jan. 2019. (Artigo em Periódico Digital)

DELEUZE, G. Crítica e clínica. Trad. Peter Pál Pelbart. São Paulo: Ed. 34, 1997.

DELEUZE, G. Sobre o teatro: um manifesto de menos; O esgotado. Trad. Fátima Saadi, Ovídio de Abreu, Roberto Machado. Rio de Janeiro: Jorge Zahar, 2010.

DELEUZE, G. Foucault. Trad. Pedro Elói Duarte. Lisboa: Edições 70, 2012.

DELEUZE, G.; GUATTARI, F. Mil platôs: capitalismo e esquizofrenia, vol. 1. Trad. Ana Lúcia de Oliveira, Aurélio Guerra Neto e Celia Pinto Costa. São Paulo: Editora 34, 1995a.

DELEUZE, G.; GUATTARI, F. Mil platôs: capitalismo e esquizofrenia, vol. 2. Trad. Ana Lúcia de Oliveira; Lúcia Cláudia Leão. São Paulo: Editora 34, 1995 b.

DELEUZE, G.; GUATTARI, F. Mil platôs: capitalismo e esquizofrenia, vol. 4. Trad. Suely Rolnik. São Paulo: Editora 34, 2012a.

DELEUZE, G.; GUATTARI, F. Mil platôs: capitalismo e esquizofrenia, vol. 5. Trad. Peter Pál Pelbert e Janice Caiafa. São Paulo: Editora 34, 2012b.

DELEUZE, G.; GUATTARI, F. Kafka: por uma literatura menor. Tradução de Cíntia Vieira da Silva. Belo Horizonte: Autêntica, 2014.

DELEUZE, G.; PARNET, C. L'Abécédaire de Gilles Deleuze. Entrevista com Gilles Deleuze. Editoração: Brasil, Ministério de Educação, "TV Escola”, 2001. Paris: Editions Montparnasse, 1997. 1 videocassete, VHS, son., color. 
DELEUZE, G.; PARNET, C. Diálogos. Trad. Eloisa Ribeiro. São Paulo: Editora Escuta, 1998.

NIETZSCHE, Friedrich Wilhelm. A gaia ciência. Trad. Paulo César de Souza. São Paulo: Companhia da Letras, 2012.

PASSOS, E.; KASTRUP, V.; ESCÓSSIA L. (Orgs.). Pistas do método da cartografia: Pesquisa-intervenção e produção de subjetividade. Porto Alegre: Sulina, 2012.

SAUVAGNARGUES, Anne. Deleuze: del animal al arte. Buenos Aires: Amorrortu, 2006.

SILVA, C. L. L. Sobre o mal-estar docente: constituindo percepções a partir de um grupo de professores da rede pública estadual de ensino do RS. 2014. 105 f. Dissertação (Mestrado em Ensino de Ciências e Matemática) - Faculdade de Educação, Universidade Federal de Pelotas, Pelotas. 2014. (Dissertação ou Tese)

SPINOZA. Ética. Trad. Tomaz Tadeu. Belo Horizonte: Autêntica Editora, 2007. 